\title{
Implementasi Automatic Waypoint untuk Return Trip pada Autonomous Robot dengan Titik Acuan Potensi Korban Bencana
}

\section{IHSAN FARRASSALAM AMMARPRAWIRA, MOCHAMAD SEPTONI FAUZI, ARBI ABDUL JABBAAR, NIKEN SYAFITRI}

\author{
Institut Teknologi Nasional Bandung, Indonesia \\ Email : prawiraihsan7@gmail.com
}

Received 23 Oktober 2019 | Revised 21 November 2019 | Accepted 15 Januari 2020

\begin{abstract}
ABSTRAK
Langkah utama dan mendasar yang diperlukan untuk navigasi pada robot secara autonomous pada medan yang tak beraturan dan tidak diketahui keadaannya secara dinamis, setidaknya adalah identifikasi koordinat titik jalan (waypoint), tindakan yang harus dilakukan di titik jalan, identifikasi dimensi kerja, dan hambatan yang diketahui. Penelitian ini bertujuan untuk mengimplementasikan titik jalan otomatis (automatic waypoint) pada robot pencari potensi keberadaan korban pasca bencana, dilengkapi dengan kemampuan robot untuk navigasi dari titik awal berjalan mencari potensi keberadaan korban sebagai titik acuan hingga kembali ke titik awal (return trip) secara autonomous. Metode yang digunakan pada perancangan sistem merupakan pengembangan dari metode waypoint menjadi automatic waypoint untuk navigasi secara autonomous. Hasil yang didapat, robot mampu mendeteksi keberadaan korban maksimal dalam radius 3 meter di dalam simulasi reruntuhan. Ketercapaian rata-rata akurasi pembacaan posisi robot terhadap korban dan titik awal sebesar 6,76 meter.
\end{abstract}

Kata kunci: robot, autonomous, automatic waypoint, korban, return trip.

\begin{abstract}
There are necessary steps required for a robot to navigate autonomously on an unknown and uncertain environment. Those steps consist of the identification of the waypoint coordinates, the actions to be conducted, the identification of the environment's dimension, and the known obstacles. This study aims to implement an automatic waypoint on a robot for searching the potential existence of post-disaster victims. The robot is equipped with the ability to navigate from the starting point to search for potential victims and then return to the starting point autonomously. We modified the existing waypoint method into an automatic waypoint for autonomous navigation. Results show that the robot is able to detect the presence of the victim within the maximum radius of 3 meters in the simulation of rubble (tables, chairs, wood and iron poles). The accuracy of robot in reading the position of the victim and the starting point is 6,76 meters.
\end{abstract}

Keywords: robot, autonomous, automatical waypoint, victims, return trip. 


\section{PENDAhuluan}

Robot merupakan salah satu teknologi yang dapat mempermudah dan mengurangi resiko dalam proses pencarian korban pasca bencana. Keuntungan dari penggunaan robot yaitu dapat memasuki daerah yang berbahaya ketika proses pencarian tanpa membahayakan anggota tim SAR itu sendiri. Dengan demikian, tindakan lebih lanjut dapat diambil ketika akan melakukan proses pertolongan (rescue). Keuntungan tersebut dapat bertambah dengan adanya sistem autonomous yang ditanamkan pada robot. Menurut penelitian yang dilakukan oleh Ahmad Sulkhan Taufik pada tahun 2013, autonomous robot adalah robot yang mampu berperilaku secara mandiri (Taufik, 2013).

Sementara itu, diperkuat oleh pernyataan Sarvapali Ramchurn dkk pada tahun 2016, bahwa operasi SAR bertujuan untuk menyelamatkan korban bencana yang masih hidup, dan waktu penyelamatan sangatlah penting. Reruntuhan di area bencana dapat memperlama proses penyelamatan tersebut, yang berakibat pada kegagalan dalam menyelamatkan korban bencana yang masih bertahan hidup (Ramchurn, 2016).

Ketidakstabilan reruntuhan dan bangunan pasca bencana juga dapat menyebabkan lamanya proses penyelamatan. Hal yang lebih buruk, reruntuhan tersebut menimpa atau menimbun korban yang masih bertahan hidup, dan akhirnya menambah jumlah korban nyawa. Kestabilan reruntuhan dan bangunan pasca bencana dapat dipertahankan dengan menyebarkan peralatan kecil (Statheropoulos, 2015). Peralatan kecil dengan massa dan dimensi yang kecil dapat meminimalisasi jatuhnya korban nyawa karena beban di atas mereka kecil.

Pada penelitian yang telah dilakukan oleh Yohanes Lucky pada tahun 2012 yaitu "Rancang Bangun Robot Penyelamat untuk Medan Reruntuhan Bangunan di Darat", joystick masih diperlukan untuk mengatur arah pergerakan dari robot tersebut dalam mencari korban, sehingga tidak autonomous. Selain itu, robot yang dirancang tidak dapat mendeteksi keberadaan korban yang masih hidup, melainkan mencari korban dengan bantuan kamera yang ditampilkan pada monitor Tim SAR. Penelitian yang dilakukan oleh Yohanes Lucky ini memiliki kelebihan, yaitu robot yang direalisasikan berupa robot dengan penggerak continuous track atau robot tank, sehingga robot dapat lebih leluasa dan seimbang melewati medan cukup berat pada area bencana dibandingkan dengan robot beroda empat pada umumnya (Wijaya, 2012).

Robot yang diimplementasikan oleh Syadza Sausan dan kawan-kawan pada tahun 2017 telah dikembangkan untuk memberi tahu tim SAR di mana posisi para korban berada dan rute aman yang harus dilalui untuk proses evakuasi (Sausan, dkk, 2017). Namun, robot ini tidak autonomous karena joystick digunakan untuk mengontrol pergerakan robot.

Melihat sistem robot dengan pergerakan autonomous, maka faktor yang sangat mempengaruhinya adalah lingkungan. Lingkungan yang dihadapi ketika melakukan pencarian korban bencana umumnya sulit, labil dan mudah berubah (karenanya berbahaya) dan sifatnya susah diprediksi. Agar robot bisa melaksanakan tugas tertentu secara autonomous pada medan yang tak beraturan dan tidak diketahui kondisinya secara dinamis, robot harus memiliki kemampuan navigasi yang handal agar mobilitasnya sangat fleksibel. Sistem navigasi pada robot untuk pencarian potensi keberadaan korban berupa penghindaran tabrakan dengan benda di sekitarnya, dan pengenalan objek sesuai dengan fitur yang disematkan pada robot, dalam hal ini adalah pengenalan keterdapatan potensi adanya korban bencana. Merujuk pada Kamus Besar Bahasa Indonesia (KBBI), "korban" dapat dikategorikan sebagai manusia ataupun hewan.

$$
\text { ELKOMIKA - } 204
$$


Implementasi Automatic Waypoint untuk Return Trip pada Autonomous Robot dengan Titik Acuan

Potensi Korban Bencana

Langkah-langkah utama dan mendasar yang diperlukan untuk navigasi pada robot berjalan (mobile robot) secara autonomous setidaknya adalah identifikasi koordinat titik jalan (waypoint), tindakan yang harus dilakukan di titik jalan, identifikasi dimensi kerja, dan hambatan yang diketahui (Balan, dkk, 2018). Beberapa penelitian pun menggunakan waypoint sebagai metode untuk navigasi mobile robot (Taufik, 2013) (Liani, dkk, 2016), (Kurniawan, 2018) (Balan, dkk, 2018) (Eslamiat, dkk, 2019).

Penggunaan waypoint pada mobile robot dapat digunakan sebagai pergerakan autonomous pada robot yang ditugaskan pada lokasi bencana, karena robot tersebut bersifat bergerak (mobile).

Dengan banyak titik acuan jalan (multi waypoint), maka transisi antara titik jalan (waypoint) dapat digunakan ketika robot meninggalkan rumah atau titik awal (home/start) atau return trip pulang ke rumah dari mana saja di lapangan untuk menyederhanakan perencanaan jalur secara real-time, seperti Catagylphis, yaitu robot pada penelitian Yu Gu, dan kawan-kawan (Gu, Y, dkk, 2018).

Penelitian yang dilakukan oleh Karthika Balan dan Chaomin Luo pada tahun 2018 menggunakan waypoint sebagai dasar pergerakan robot yang dapat diterapkan pada lokasi bencana. Robot yang dibangun dapat memilih jalur terpendek untuk dilalui yang bisa digunakan untuk pencarian potensi keberadaan korban atau return trip tercepat ke posisi awal. Percobaan yang dilakukan adalah memasukkan atau meng-input 10 buah titik jalan (waypoint) oleh operator sebagai referensi (Balan, dkk, 2018).

Dengan input berupa titik jalan (waypoint) yang dimasukkan oleh operator, membuat robot tidak bisa menjalankan tugasnya jika input tersebut tidak diberikan. Selain itu, walaupun pergerakannya autonomous, namun sistem keseluruhan tidak bisa dikatakan autonomous karena tetap menunggu perintah dari operator. Artinya sistem tidak dapat menjalankan tugasnya secara mandiri. Pada robot pendeteksi adanya potensi korban bencana, jika robot menggunakan input waypoint dari operator agar robot dapat bergerak mencari potensi keberadaan korban dan kembali ke posisi awal (return trip), tentu akan membuat peranan tambahan. Misalnya, robot ingin kembali ke posisi awal (return trip) pada saat selesai melakukan pencarian keberadaan korban, namun robot tidak tahu di mana posisi awal tersebut berada. Pada saat titik jalan (waypoint) diberikan oleh operator, barulah robot dapat berjalan hingga ke posisi awal.

Berdasarkan permasalahan yang dihadapi, maka penelitian ini bertujuan untuk mengimplementasikan robot pendeteksi potensi keberadaan korban bencana. Posisi potensi korban tersebut dijadikan input otomatis sebagai titik jalan (waypoint) untuk pergerakan autonomous kembali ke posisi awal (return trip). Input waypoint atau masukan titik jalan yang semula dilakukan oleh operator diubah dengan pembacaan titik jalan pada saat pertama kali robot start dan titik potensi keberadaan korban sebagai titik acuan. Semua pembacaan titik jalan (waypoint) menggunakan koordinat berupa latitude dan longitude. Dengan perubahan tersebut akan membuat robot dapat bergerak secara autonomous sesuai titik jalan (waypoint) tanpa adanya perintah manual dari operator.

\section{METODOLOGI PENELITIAN}

\subsection{Perancangan Sistem}

Implementasi automatic waypoint untuk return trip pada autonomous robot dengan titik acuan potensi keberadaan korban bencana ini memiliki tujuan menghasilkan robot pencari

$$
\text { ELKOMIKA - } 205
$$


potensi keberadaan korban bencana alam yang masih hidup tanpa adanya bantuan tangan manusia secara langsung. Implementasi ini akan dicapai dan dilengkapi dengan kemampuan robot untuk navigasi dari titik awal berjalan mencari potensi keberadaan korban sebagai titik acuan hingga kembali ke titik awal (return trip) secara autonomous.

Automatic waypoint dirancang dengan mengubah input waypoint atau masukan titik jalan yang semula dilakukan oleh operator dengan pembacaan titik jalan pada saat pertama kali robot start menggunakan GPS. Robot dibiarkan bernavigasi dengan berjalan acak dan mendeteksi keberadaan korban di sekitarnya dibantu dengan sensor ultrasonik untuk penghindaran tabrakan dengan objek di sekitar. Jika robot berhasil mendeteksi adanya pergerakan kecil di balik reruntuhan atau di luar reruntuhan yang disinyalir merupakan korban, maka robot akan mengirimkan posisi ter-update berupa titik koordinat longitude dan latitude kepada operator secara nirkabel melalui LoRa, dan melanjutkan pencarian kembali. Pengujian dibatasi dengan mencari tiga korban (naracoba), setelah itu robot kembali ke koordinat atau posisi awal (start), perjalanan pulang (return trip) tidak mengikuti proses perjalanan awal. Berikut Gambar 1 menggambarkan diagram blok sistem yang dirancang.

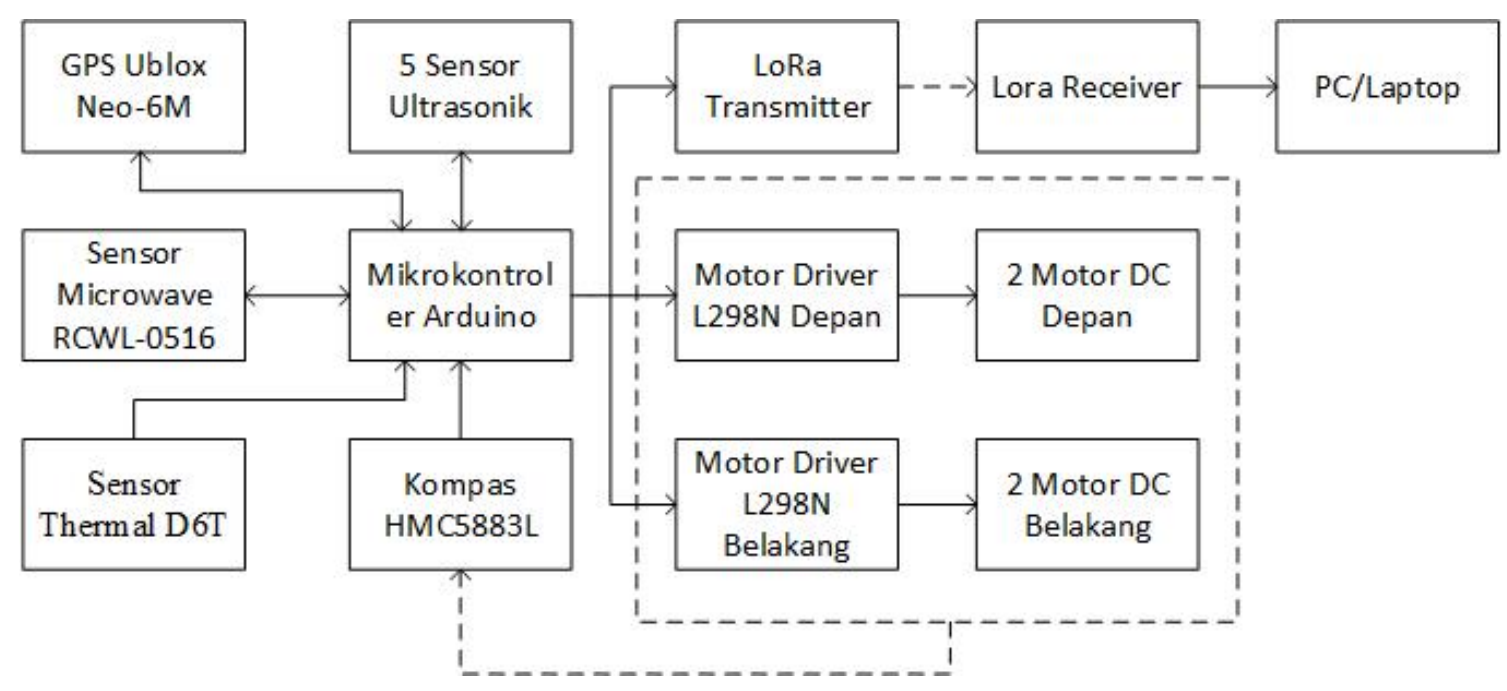

Gambar 1. Diagram Blok Sistem

Berdasarkan diagram blok sistem pada Gambar 1, GPS UBlox Neo-6M akan memberikan informasi berupa koordinat latitude dan longitude yang akan digunakan pada penentuan titik jalan (waypoint) pergerakan robot. Sensor Microwave RCWL-0516 akan mengirimkan informasi mengenai adanya potensi pergerakan kecil di balik reruntuhan yang disinyalir merupakan korban bencana, dan sensor thermal D6T akan membantu mendeteksi adanya potensi keberadaan korban melalui suhu tubuh. Sensor ultrasonik ditempatkan mulai dari samping kiri, tengah hingga samping kanan sebanyak lima buah untuk menghindari tabrakan dengan objek di sekitar robot. Kompas HMC5883L akan membaca heading robot atau sudut arah robot untuk kemudahan dalam pergerakan secara autonomous. Mikrokontroler yang disematkan pada robot adalah Arduino (ATMega2560). Motor Driver L298N akan menggerakkan motor DC sebanyak empat buah (4WD) dengan konfigurasi dua buah motor DC di depan dan dua buah motor DC di belakang. Seluruh informasi koordinat atau posisi korban akan dikirimkan melalui LoRa secara wireless dan ditampilkan pada serial monitor di PC atau laptop pengguna. 


\subsection{Diagram Alir Sistem}

Waypoint dirancang untuk mengatur gerak autonomous mobile robot dalam mencapai posisi tujuan. Sistem navigasi dirancang agar robot mampu mengenali posisi dan arah berdasarkan sistem koordinat bumi, dan mampu melakukan koreksi arah gerak (bearing correction), diperjelas pada Gambar 2 sebagai diagram alir sistem.
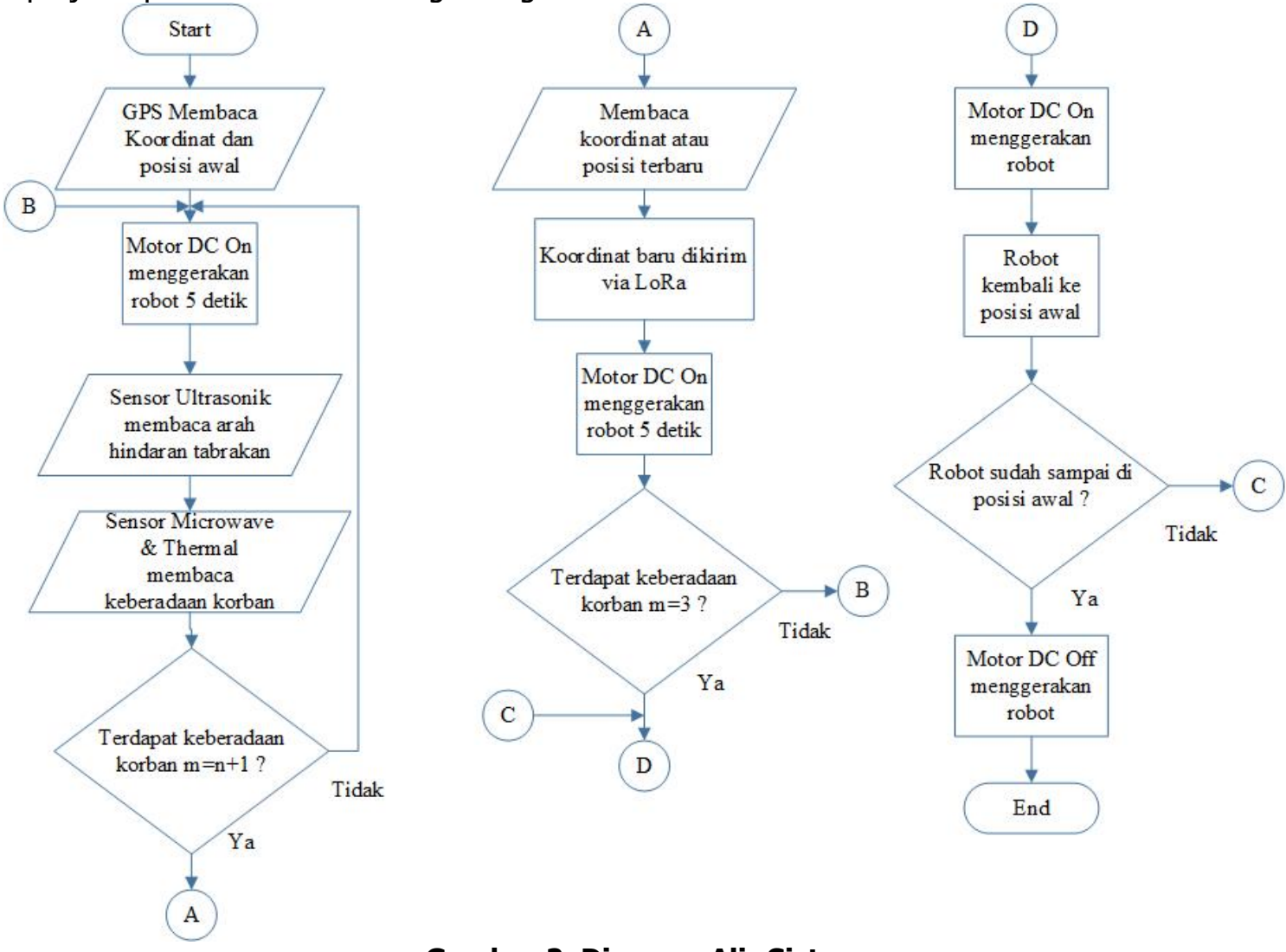

Gambar 2. Diagram Alir Sistem

Pada Gambar 2, digambarkan diagram alir dari sistem keseluruhan. Pertama, pada saat start terlebih dahulu GPS membaca posisi robot berupa koordinat longitude dan latitude. Hal tersebut sebagai penentu titik jalan (waypoint) pada saat robot akan kembali ke posisi awal setelah melakukan pencarian korban. Setelah berhasil mendapatkan data koordinat, robot dibiarkan berjalan secara bebas selama 5 detik dengan penghindaran tabrakan di sekelilingnya. Robot dibiarkan berjalan selama 5 detik pada lingkungan outdoor dengan pengujian di track lurus, hal tersebut karena sensor microwave RCWL-0516 memiliki prinsip kerja modul sensor gerak motion gelombang mikro radar doppler, bekerja dengan membaca perubahan gelombang suara di sekitar dan sensor tersebut memiliki spesifikasi dapat membaca pergerakan hingga 7 meter jarak objek terhadap sensor tanpa halangan berarti. Jika robot bergerak, sensor microwave yang tertanam pada robot akan mendeteksi adanya pergerakan motion sehingga pendeteksian korban akan terganggu dengan pergerakan dari robot. Karena itu pada sistem ini di-setting pergerakan robot selama 5 detik berdasarkan asumsi bahwa dengan kecepatan yang diinginkan robot sebesar $1 \mathrm{~m} / \mathrm{s}$ pada track lurus (pengujian), sensor microwave dapat mendeteksi keberadaan kemungkinan pergerakan kecil dari korban berupa pergerakan tangan, ataupun hal lainnya setiap radius kurang dari 5 meter. Selain menggunakan sensor microwave, pendeteksian potensi keberadaan korban juga menggunakan sensor thermal dengan tipe D6T dari Omron. Sensor thermal D6T dapat mendeteksi adanya suhu tubuh manusia hingga 8 meter tanpa halangan. Pada pengujian 
yang akan dilakukan, keberadaan korban akan dibatasi sebanyak tiga buah dengan memasukkan variabel $m=n+1$. Setiap robot berhasil mendeteksi adanya kemungkinan korban, maka GPS akan membaca koordinat terbaru dan mengirimkan informasi tersebut ke PC/laptop operator via LoRa dengan maksimum jarak $10 \mathrm{~km}$ sesuai spesifikasi yang digunakan. Dengan jumlah total yang diatur sebanyak $\mathrm{m}=3$, artinya jumlah pendeteksian sudah mencapai tiga korban, maka robot akan kembali ke posisi awal (return trip) sesuai koordinat pembacaan start paling pertama. Robot akan memastikan apakah posisi kembali ke awal atau start sudah tepat dengan membandingkan kembali pembacaan terbaru dari GPS.

\subsection{Implementasi Sistem}

Robot yang diimplementasikan pada kegiatan penelitian ini adalah robot dengan jenis efektor continuous track atau robot tank. Berikut Gambar 3 menunjukkan robot yang digunakan pada kegiatan penelitian ini.

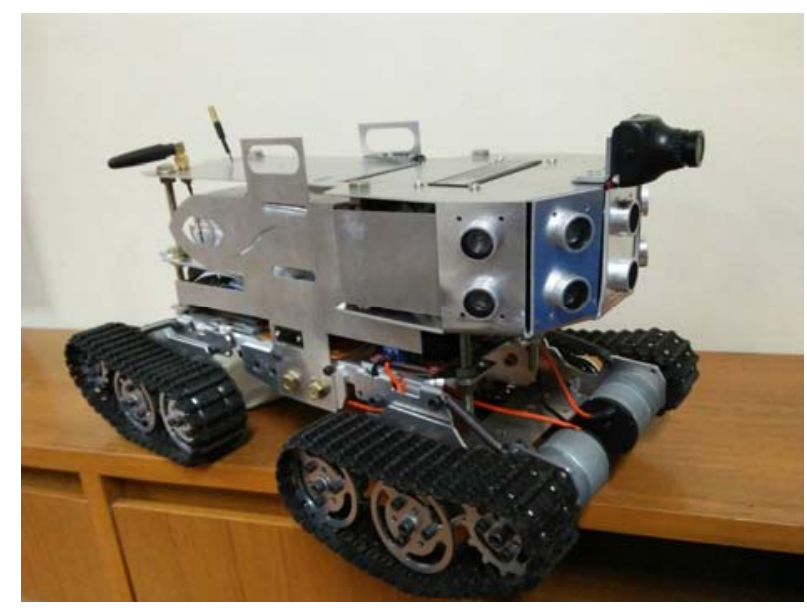

Gambar 3. Implementasi Robot

\subsection{Metode Pengujian}

Pengujian yang dilakukan adalah melakukan uji sensor microwave dalam mendeteksi keberadaan kemungkinan korban, kalibrasi kompas untuk heading sudut robot, uji pembacaan koordinat GPS, dan keberhasilan robot dalam mendeteksi kemungkinan keberadaan korban, pembacaan koordinat korban dan return trip ke posisi awal start.

Pengujian untuk mendeteksi keberadaan korban (naracoba) menggunakan sensor microwave RCWL-0516 dan sensor thermal D6T. Naracoba ditempatkan di balik reruntuhan (berupa meja, kursi, kayu dan tiang besi) setiap $50 \mathrm{~cm}$ atau 0,5 m, mengikuti lebar dan panjang (dimensi) reruntuhan. Berikut Gambar 4 menggambarkan simulasi reruntuhan yang digunakan.

Reruntuhan pada simulasi ini merupakan asumsi yang diperkirakan ada pada benda-benda pasca bencana di suatu lokasi. Kompas HMC5883L yang digunakan perlu dikalibrasi ulang agar pembacaan arah sudut tidak salah. GPS yang digunakan pada sistem yang diimplementasikan adalah GPS UBlox Neo-6M. GPS ditempatkan pada posisi yang tetap dan dibiarkan untuk mendeteksi koordinat secara berulang. Hal tersebut untuk mengetahui seberapa presisi dan error yang terdapat pada modul GPS tersebut. Pembacaan koordinat latitude dan longitude akan sangat berpengaruh terhadap keterdapatan posisi korban. 


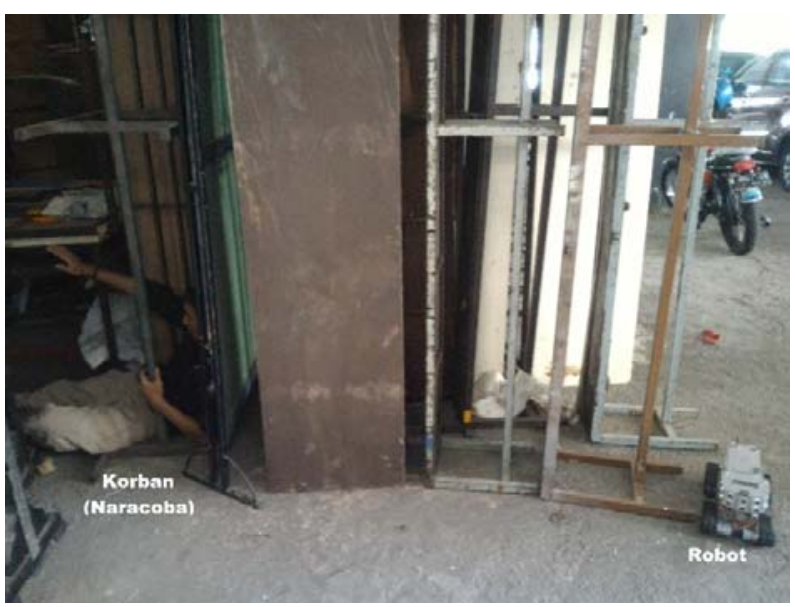

\section{Gambar 4. Simulasi Reruntuhan}

Pengujian terakhir adalah keberhasilan robot dalam mendeteksi keberadaan korban yang sudah ditentukan posisinya dengan membandingkan hasil pembacaan titik koordinat dari GPS terhadap titik koordinat melalui google maps, dan keberhasilan robot dalam perjalanan kembali (return trip) dalam mencapai titik koordinat awal start.

Analisis yang akan dilakukan adalah ketercapaian pembacaan koordinat latitude dan longitude robot pada saat pendeteksian kemungkinan keberadaan manusia yang sudah diatur dan ketercapaian robot dalam perjalanan kembali (return trip) dalam mencapai titik koordinat awal start.

Pengujian dibatasi dengan ketentuan sebagai berikut:

1. Jumlah Korban (naracoba) sebanyak tiga orang.

2. Slip diabaikan.

3. Simulasi reruntuhan sesuai dengan benda yang ada berupa (meja, kursi, kayu dan tiang besi).

4. Pengujian pendeteksian masing-masing korban (naracoba) sebanyak sepuluh kali.

5. Dilakukan pada area terbuka dengan luas minimal 10 meter.

\section{HASIL DAN PEMBAHASAN}

\subsection{Pengujian Deteksi Korban (Naracoba)}

Pengujian untuk mendeteksi keberadaan korban (naracoba) berupa manusia dan hewan (kucing) menggunakan sensor microwave dan thermal, naracoba ditempatkan di balik reruntuhan (berupa meja, kursi, kayu dan tiang besi) setiap $50 \mathrm{~cm}$ atau $0,5 \mathrm{~m}$, mengikuti lebar dan panjang (dimensi) reruntuhan, dan untuk sensor thermal ditambah dengan pengujian tanpa halangan (reruntuhan). Tabel 1 menunjukkan data pengujian sensor microwave \& sensor thermal yang ditanamkan pada robot pada saat mendeteksi korban (naracoba). 
Tabel 1. Data Pengujian Deteksi Korban (Naracoba)

\begin{tabular}{|c|c|c|c|c|c|c|}
\hline \multicolumn{3}{|c|}{ Sensor Microwave (Halangan) } & \multicolumn{2}{c|}{$\begin{array}{c}\text { Sensor Thermal } \\
\text { (Halangan) }\end{array}$} & $\begin{array}{c}\text { Sensor Thermal (Tanpa } \\
\text { Halangan) }\end{array}$ \\
\hline No & $\begin{array}{c}\text { Jarak } \\
(\mathbf{m})\end{array}$ & Keterangan & $\begin{array}{c}\text { Jarak } \\
(\mathbf{m})\end{array}$ & Keterangan & $\begin{array}{c}\text { Jarak } \\
(\mathbf{m})\end{array}$ & Keterangan \\
\hline 1 & 0 & Terdeteksi & 0 & Tidak Terdeteksi & 0 & Terdeteksi \\
\hline 2 & 0,5 & Terdeteksi & 0,5 & Tidak Terdeteksi & 1 & Terdeteksi \\
\hline 3 & 1 & Terdeteksi & 1 & Tidak Terdeteksi & 2 & Terdeteksi \\
\hline 4 & 1,5 & Terdeteksi & 1,5 & Tidak Terdeteksi & 3 & Terdeteksi \\
\hline 5 & 2 & Terdeteksi & 2 & Tidak Terdeteksi & 4 & Terdeteksi \\
\hline 6 & 2,5 & Terdeteksi & 2,5 & Tidak Terdeteksi & 5 & Terdeteksi \\
\hline 7 & 3 & Terdeteksi & 3 & Tidak Terdeteksi & 6 & Terdeteksi \\
\hline 8 & 3,5 & Tidak Terdeteksi & 3,5 & Tidak Terdeteksi & 7 & Tidak Terdeteksi \\
\hline 9 & 4 & Tidak Terdeteksi & 4 & Tidak Terdeteksi & 8 & Tidak Terdeteksi \\
\hline
\end{tabular}

Dari data yang didapat pada Tabel 1 , sensor microwave berhasil mendeteksi keberadaan korban (naracoba) di balik reruntuhan yang sudah ditetapkan. Artinya robot bencana yang ditanamkan sensor tersebut dapat mendeteksi potensi keberadaan korban (naracoba) maksimal 3 meter dibalik reruntuhan. Dan sensor thermal dapat mendeteksi keberadaan korban (naracoba) maksimal 6 meter tanpa halangan. Sensor thermal dipergunakan untuk membantu pendeteksian korban (naracoba) berdasarkan suhu atau panas tubuh korban (naracoba). Kondisi ideal gabungan penggunaan sensor microwave dan thermal dalam deteksi korban sejauh 3 meter baik di balik reruntuhan ataupun di luar reruntuhan. Berikut Gambar 5 menggambarkan pengujian pendeteksian korban (naracoba) pada jarak 3 meter, dan Gambar 6 merupakan tampilan pada serial monitor PC/Laptop mengenai informasi robot berhasil mendeteksi adanya korban.

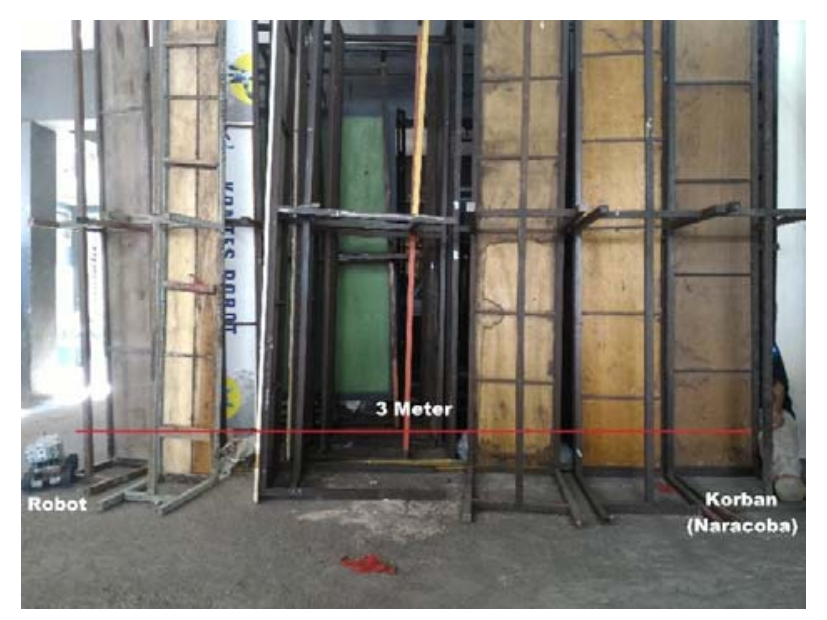

Gambar 5. Pendeteksian Korban pada Jarak 3 Meter 
LoRa Receiver

Korban Terdeteksi

\section{Gambar 6. Tampilan Serial Monitor pada PC/Laptop Mengenai Informasi Pendeteksian Korban}

Serial monitor pada PC/Laptop menunjukkan kalimat seperti pada Gambar 6, menandakan bahwa sensor pendeteksian korban yang diimplementasikan pada robot yaitu sensor microwave dan sensor thermal atau salah satunya berhasil mendeteksi adanya korban (naracoba).

\subsection{Pengujian GPS}

GPS yang digunakan pada sistem yang diimplementasikan adalah GPS UBlox Neo-6M. GPS ditempatkan pada posisi yang tetap dan dibiarkan untuk mendeteksi koordinat secara berulang. Posisi koordinat terlebih dahulu diketahui berdasarkan pembacaan dari google maps.

Tabel 2. Pengujian Pembacaan GPS pada Koordinat Tetap

\begin{tabular}{|c|c|c|c|c|}
\hline \multicolumn{5}{|c|}{ Koordinat (-6.897974, 107.635704) } \\
\hline \multirow{2}{*}{ Rata - rata } & Latitude & Longitude & Selisih Latitude & Selisih Longitude \\
\cline { 2 - 5 } & -6.8980084 & 107.635704 & 0.000034 & 0 \\
\hline
\end{tabular}

Berdasarkan data pengujian GPS pada Tabel 2, pembacaan GPS rata-rata pada titik atau posisi yang sama untuk latitude sebesar -6.8980084 dan untuk longitude sebesar 107.635704. Pembacaan latitude berubah-ubah, sedangkan longitude tidak berubah. Melihat pada Gambar 7, berupa jarak rata-rata koordinat pembacaan terhadap koordinat tetap pada google earth sebagai berikut:

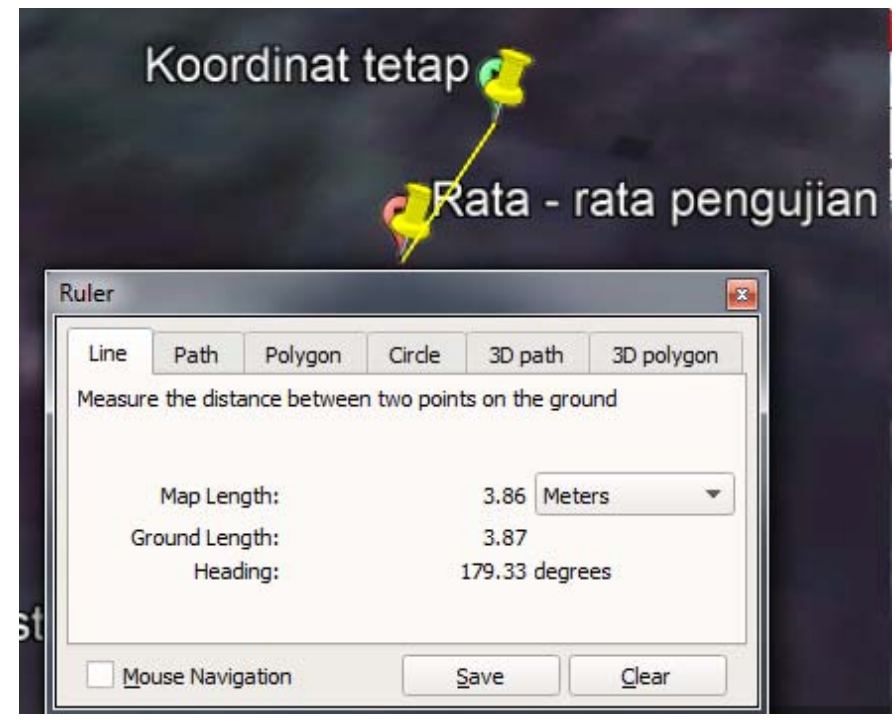

Gambar 7. Jarak antara Rata-rata Pembacaan Koordinat GPS terhadap Koordinat Tetap (Google Earth, 2019)

ELKOMIKA - 211 
Selisih jarak yang didapat dari rata-rata pembacaan koordinat GPS dengan koordinat tetap (referensi) sebesar 3,87 meter. Pembacaan awal 27 detik merupakan asumsi kondisi GPS pada saat pertama kali dijalankan, pembacaan koordinat dilakukan setiap detik. Pengaruh jarak pembacaan rata-rata menggunakan GPS Ublox Neo-6m bisa dipengaruhi oleh hal lain, yaitu koordinat tetap sebagai referensi yang dibaca melalui google maps, pembacaan melalui google maps pastinya memiliki error.

\subsection{Pengujian Pendeteksian Posisi Korban}

Pengujian pendeteksian posisi korban (naracoba) dilakukan dengan menempatkan naracoba di balik reruntuhan (simulasi) yang sudah disiapkan. Posisi koordinat korban terlebih dahulu diketahui berdasarkan pembacaan dari google maps, dan robot dibiarkan berjalan untuk serta mengirimkan posisi robot ketika berhasil mendeteksi keberadaan korban (naracoba) berupa latitude dan longitude melalui LoRa. Berikut Gambar 8 menggambarkan tampilan pada serial monitor PC/Laptop ketika GPS pada robot mengirimkan informasi koordinat korban melalui LoRa.

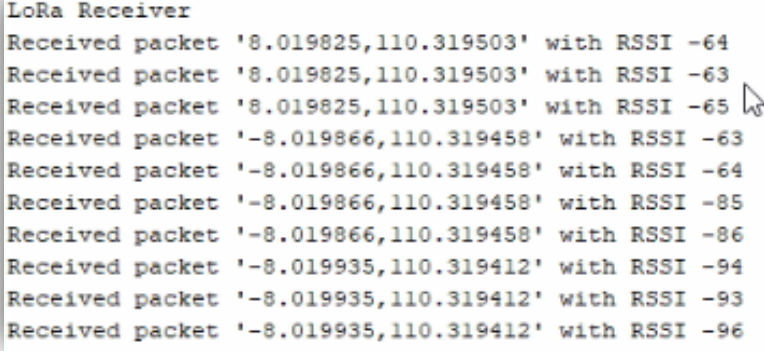

\section{Gambar 8. Tampilan Serial Monitor pada PC/Laptop Mengenai Informasi Koordinat Korban}

Berikut Tabel 3 menunjukkan hasil pembacaan koordinat posisi robot pada saat mendeteksi adanya korban yang didapat dari tampilan informasi pada serial monitor PC/Laptop seperti Gambar 8, baik itu (naracoba) pertama hingga ketiga, dan ketercapaian posisi robot terhadap titik awal (start):

Tabel 3. Pendeteksian Posisi Robot terhadap Korban

\begin{tabular}{|l|c|c|c|c|}
\hline \multicolumn{5}{|c|}{ Koordinat Korban Pertama (-6.897989, 107.635682) } \\
\hline \multirow{2}{*}{ Rata - rata } & Latitude & Longitude & Selisih Latitude & Selisih Longitude \\
\cline { 2 - 5 } & -6.8980347 & 107.635678 & 0.000046 & 0.000009 \\
\hline \multicolumn{5}{|c|}{ Koordinat Korban Kedua (-6.897976, 107.635585) } \\
\hline \multirow{2}{*}{ Rata - rata } & Latitude & Longitude & Selisih Latitude & Selisih Longitude \\
\cline { 2 - 5 } & -6.8980116 & 107.635583 & 0.0000356 & 0.0000192 \\
\hline \multicolumn{5}{|c|}{ Koordinat Korban Ketiga (-6.897954, 107.635431) } \\
\hline \multirow{2}{*}{ Rata - rata } & Latitude & Longitude & Selisih Latitude & Selisih Longitude \\
\cline { 2 - 5 } & -6.8979764 & 107.6354586 & 0.0000316 & 0.0000288 \\
\hline \multirow{2}{*}{ Kota - rata } & Latitude & Longitude & Selisih Latitude & Selisih Longitude \\
\cline { 2 - 5 } & -6.8980402 & 107.6357088 & 0.0000148 & 0.0000352 \\
\hline
\end{tabular}


Seluruh koordinat pada Tabel 3 diolah kembali melalui google earth agar tampilannya menjadi visual dan lebih mudah untuk dianalisis, seperti pada Gambar 9, 10, 11, dan 12 sebagai berikut:

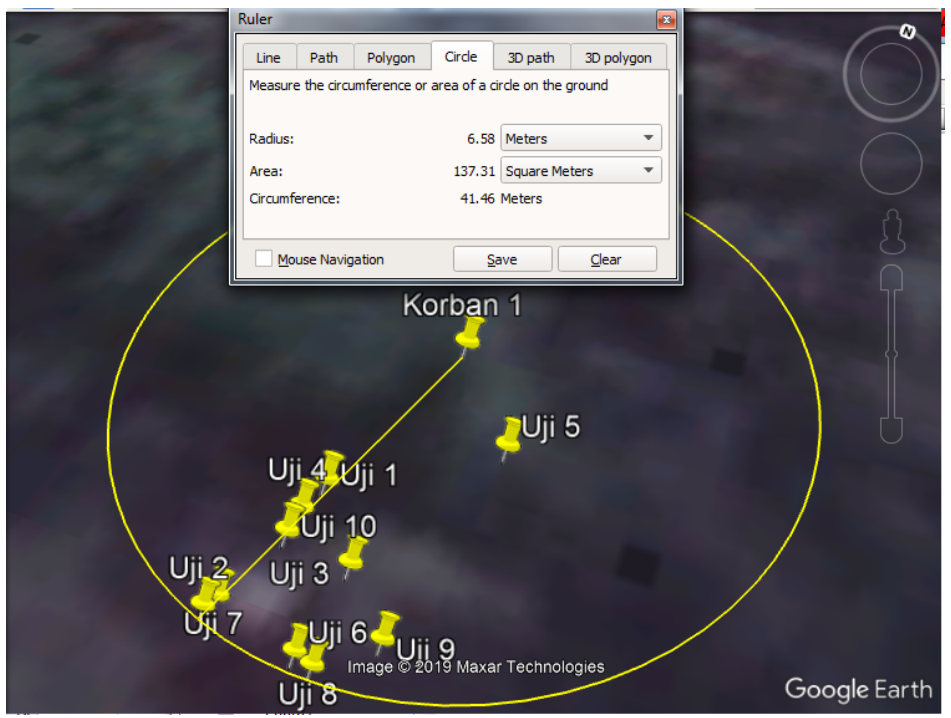

\section{Gambar 9. Jarak antara Pembacaan Posisi Robot terhadap Korban Pertama (Google Earth, 2019)}

Gambar 9 menunjukkan pembacaan posisi robot terhadap korban pertama dengan pengujian 10 kali yang ditandai dengan bagian uji 1-uji 10. Posisi korban pertama pada Gambar 9 merupakan pembacaan koordinat melalui google maps. Berdasarkan plot koordinat-koordinat tersebut pada google earth, radius pembacaan posisi robot terhadap korban pertama sebesar 6,58 meter.

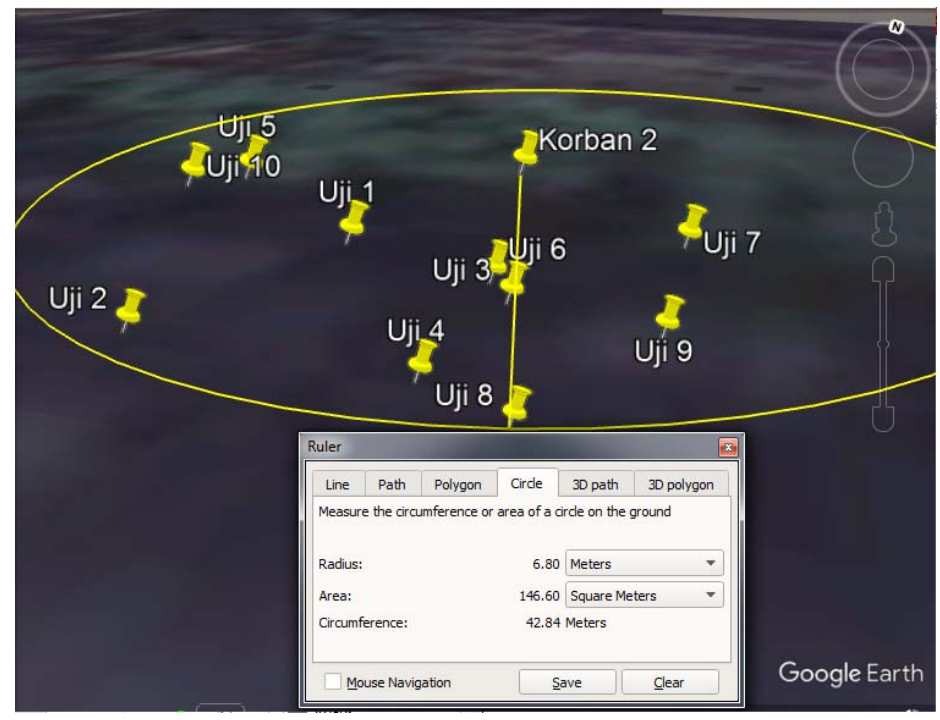

Gambar 10. Jarak antara Pembacaan Posisi Robot terhadap Korban Kedua (Google Earth, 2019) 
Gambar 10 menunjukkan pembacaan posisi robot terhadap korban kedua dengan pengujian 10 kali yang ditandai dengan bagian uji 1-uji 10. Posisi korban kedua pada Gambar 10 merupakan pembacaan koordinat melalui google maps. Berdasarkan plot koordinat-koordinat tersebut pada google earth, radius pembacaan posisi robot terhadap korban kedua sebesar 6,80 meter.

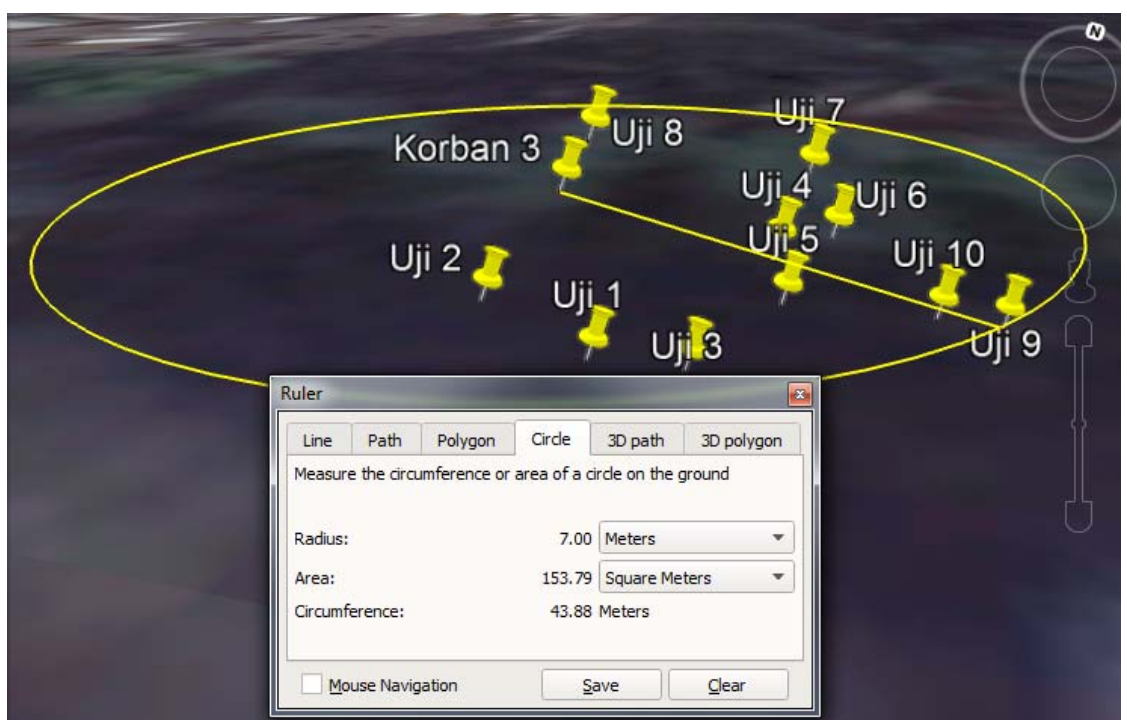

\section{Gambar 11. Jarak antara Pembacaan Posisi Robot terhadap Korban Ketiga (Google Earth, 2019)}

Gambar 11 menunjukkan pembacaan posisi robot terhadap korban ketiga dengan pengujian 10 kali yang ditandai dengan bagian uji 1-uji 10. Posisi korban ketiga pada Gambar 11 merupakan pembacaan koordinat melalui google maps. Berdasarkan plot koordinat-koordinat tersebut pada google earth, radius pembacaan posisi robot terhadap korban ketiga sebesar 7 meter.

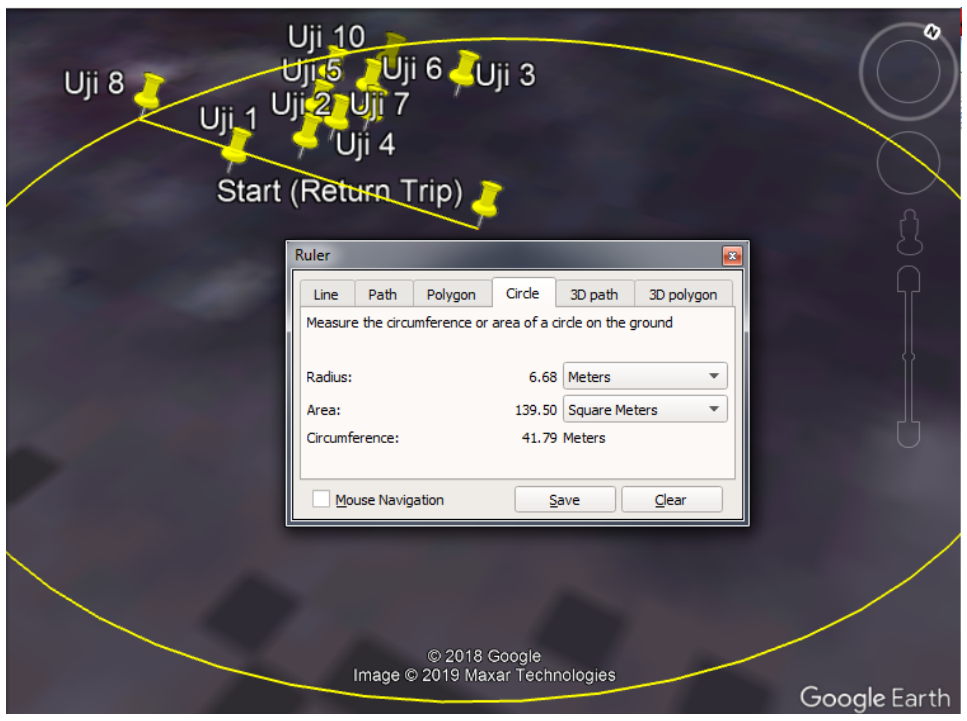

\section{Gambar 12. Jarak antara Pembacaan Posisi Robot terhadap Titik Awal (Start) (Google} Earth, 2019) 
Gambar 12 menunjukkan pembacaan posisi robot terhadap titik awal (start) pada saat return trip dengan pengujian 10 kali yang ditandai dengan bagian uji 1-uji 10. Posisi titik awal (start) pada Gambar 12 merupakan pembacaan koordinat melalui google maps. Berdasarkan plot koordinat-koordinat tersebut pada google earth, radius pembacaan posisi robot terhadap titik awal (start) sebesar 6,68 meter.

Gambar 9, 10, dan 11 menunjukkan titik-titik pembacaan posisi robot ketika berhenti berjalan selama 5 detik dan mendeteksi adanya potensi korban. Pengujian dilakukan sebanyak sepuluh kali, korban (naracoba) ditempatkan di balik reruntuhan, jarak antara korban (naracoba) terhadap lintasan robot sekitar 1-2 meter mengikuti tebal reruntuhan. Dengan akurasi pembacaan GPS rata-rata yang telah diuji sebesar 3,87 meter dan posisi robot berhenti tidak pada titik yang sama dengan korban (naracoba) membuat hasil yang didapat mengikuti pembacaan GPS pada pengujian terjauh dari masing-masing pengujian sebanyak 20 kali. Jika diambil rata-rata ketercapaian pembacaan posisi robot terhadap korban (naracoba), pembacaan posisi robot berdasarkan koordinat memiliki radius sebesar 6,76 meter. Radius tersebut masuk dalam toleransi untuk pembacaan potensi posisi korban dengan sensor RCWL-0516 yang memiliki range pendeteksian maksimal sejauh 9 meter. Sehingga masih dapat mendeteksi keberadaan korban (naracoba).

Gambar 12 menunjukkan ketercapaian robot pada saat return trip kembali ke titik awal (start) dan mendapatkan hasil pembacaan koordinat dalam radius sebesar 6,68 meter. Batas toleransi jarak yang diberikan pada program sebesar 4 meter mengikuti hasil pembulatan pembacaan pada saat pengujian GPS. Radius yang didapat lebih dari 4 meter dapat dipengaruhi oleh pembacaan koordinat GPS pada saat robot menyentuh sisi terluar lingkaran dengan radius 4 meter. Ditambah dengan toleransi pembacaan koordinat GPS sebesar 3,86 meter, maka posisi robot akan terbaca lebih dari 4 meter dari titik awal (start).

\section{KESIMPULAN}

\subsection{Kesimpulan}

Berdasarkan hasil penelitian dan analisis, terdapat beberapa hal yang dapat disimpulkan sebagai berikut:

1. Sensor microwave RCWL-0516 yang digunakan dapat mendeteksi potensi keberadaan korban di balik reruntuhan yang telah ditetapkan (berupa meja, kursi, kayu dan tiang besi) sejauh maksimal 3 meter.

2. Sensor thermal dapat mendeteksi potensi keberadaan korban (naracoba) maksimal sejauh 6 meter tanpa halangan.

3. GPS UBlox Neo-6m yang digunakan pada penelitian ini memiliki akurasi pembacaan rata-rata 3,86 meter.

4. Ketercapaian pendeteksian korban dalam radius yang cukup besar, korban pertama 6,58 meter, korban kedua 6,80 meter, dan korban ketiga 7 meter.

5. Radius terbesar pendeteksian korban masih dalam range spesifikasi sensor microwave RCWL-0516 sebesar 9 meter dan sensor thermal D6T sebesar 8 meter.

6. Ketercapaian posisi robot return trip menuju posisi start dalam radius sebesar 6,68 meter, radius yang didapat merupakan penambahan posisi robot yang menyentuh radius terluar 4 meter dan akurasi rata-rata pengujian GPS sebesar 3,86 meter. 


\subsection{Saran}

Berdasarkan hasil penelitian yang didapat, terdapat beberapa saran pengembangan untuk dapat dijadikan referensi bagi siapapun yang akan melakukan penelitian lebih lanjut terkait topik ini, yaitu:

1. Pengembangan terkait dengan akurasi pembacaan GPS yang lebih baik.

2. Pengembangan terkait dengan pendeteksian potensi keberadaan korban dengan tingkat akurasi korban nyata yang lebih baik.

3. Penggunaan sistem automatical waypoint yang dapat dikembangkan dengan pergerakan antar lebih dari satu buah robot.

4. Penggunaan efektor yang lebih baik untuk menghindari terjadinya slip di berbagai permukaan.

\section{UCAPAN TERIMA KASIH}

Terima kasih kepada Belmawa Ristekdikti yang telah memberikan bantuan dana hibah penelitian PKM kepada penulis, dan TIM Program Kreativitas Mahasiswa - Karsa Cipta (PKM$\mathrm{KC})$ yang telah membantu dan men-support pelaksanaan penelitian ini.

\section{DAFTAR RUJUKAN}

Balan K., \& Luo C. (2018). Optimal Trajectory Planning for Multiple-waypoint Path Planning using Tabu Search. The 9th IEEE Annual Ubiquitous Computing, Electronics and Mobile Communication Conference (IEEE-UEMCON'2018).

Eslamiat, H., dkk. (2019). Autonomous Waypoint Planning, Optimal Trajectory Generation and Nonlinear Tracking Control for Multi-rotor UAVs. European Control Conference 2019.

Gu, Y., dkk. (2018). Cataglyphis: An autonomous sample return rover: GU et al. Journal of Field Robotics, 00, 1-27. DOI: 10.1002/rob.21737.

Kurniawan. (2018). Rancang Bangun Prototipe Robot Pengangkut Barang Dengan Menggunakan Mikrokontroler. (skripsi). Surabaya: Program Studi Informatika, Fakultas Teknologi Informasi, Universitas Ciputra.

Liani, D., Silvia, A., dan Lindawati, L. (2016). Sistem Navigasi pada Mobile Robot dengan Global Positioning System (GPS). Annual Research Seminar 2016, (pp. 373 - 376).

Ramchurn, S. D., Wu, F., Jiang, W., Fischer, J. E., Reece, S., Robert, S., Greenhalgh, C., Rodden, T., \& Jennings, N. R. (2016). Human-agent collaboration for disaster response. Autonomous Agents and Multi-Agent Systems, 30(1), 82-111.

Sausan, S., dkk. (2017). Robot Pointer sebagai Penunjuk Jalan Tim SAR untuk Mempermudah Pencarian Korban Bencana Gempa. Jurnal Rekayasa Elektrika, 13(2), 112-118. 
Implementasi Automatic Waypoint untuk Return Trip pada Autonomous Robot dengan Titik Acuan Potensi Korban Bencana

Statheropoulos, M., Agapiou, A., Pallis, G. C., Mikedi, K., Karma, S., Vamvakari, J., Dandoulaki, M., Andritsos, F., \& Thomas, C. L. P. (2015). Factors that affect rescue time in urban search and rescue. Nat. Hazards, 75(1), 57-69.

Taufik, S. A. (2013). Sistem Navigasi Waypoint pada Autonomous Mobile Robot. (Skripsi). Malang : Jurusan Teknik Elektro Universitas Brawijaya Malang.

Wijaya, Y. L. (2012). Rancang Bangun Robot Penyelamat Untuk Medan Reruntuhan Bangunan di Darat. (skripsi). Surabaya : Jurusan Elektro, Fakultas Teknik, Universitas Surabaya. 